Original Research Paper

\title{
Constructions in the Classroom: Examples of a Phraseodidactic Approach for the Teaching of L2 French
}

\author{
Amanda Edmonds \\ University of Pau, France
}

Article history

Received: 14-03-2015

Revised: 08-05-2015

Accepted: 08-05-2015

Email: amanda.edmonds@univ-pau.fr

\begin{abstract}
Language learners and language teachers alike have long recognized the fact that there is more to learning a second language than simply learning grammar and vocabulary words. Such an approach misses the fact that there are certain sequences that are preferred by the native speaker, despite the very large number of possible formulations in any given language. Many terms have been used to refer to these preferred sequences, including formulaic language and phraseological units. However, these sequences occupy a more or less important position depending on one's theoretical underpinnings. In the current article, insights from an approach to language informed by construction grammar will be used in order to make suggestions concerning the teaching of constructions. The article will end with two specific and concrete pedagogical interventions for the teaching of French as a foreign language.
\end{abstract}

Keywords: Phraseodidactics, Phraseology, Didactics, Construction Grammar

\section{Introduction}

In a recent publication, Wray (2013) observed that "[f]or as long as language learning is construed or practiced as the assemblage of single words using repeatable rules, formulaic language, under this definition, will be inherently troublesome to learners." (p. 317). The troublesomeness referred to by Wray concerns the fact that formulaic language cannot be successfully accounted for by a strict grammar + lexicon approach to language. Although this type of modular approach allows for the generation of an infinite number of grammatical phrases, it is incapable of explaining (and, thus, allowing the language learner to understand) why, for example, absolument sûr is much more common - and, thus, presumably preferred - in native French than the similar (and also entirely grammatical) string complètement sûr (Edmonds, 2013). As has been stressed more and more in the didactic and second language (L2) acquisition literature, there is much more to speaking a language than to producing grammatical sequences; one must know which of the myriad grammatical sequences that exist are in fact preferred by native speakers (NS) in a given context to express a given meaning. This problem of native-like selection (Pawley and Syder, 1983), which is daunting for language learners and language teachers alike, pleads for the need to give more attention in the language classroom to those sequences that are in fact preferred by NSs. In other words, formulaic sequences need to play a more important role in language teaching.

This idea has given rise to much research into how learners acquire formulaic sequences and into how language teachers may best address this aspect of linguistic competence in the classroom. For English as a foreign language, Lewis' (1993) Lexical Approach has arguably been the most influential teaching method to date (Wray, 2000). For other languages, the idea of a phraseodidactic approach to language teaching has also been gaining ground (for an overview, see González-Rey, 2010). According to González-Rey, a phraseodidactic approach aims to allow learners to acquire an active phraseological competence in their L2. By placing formulaic language (which is also referred to as phraseological units) at the heart of an approach to language teaching, such authors attempt to offer an alternative to the conspicuous absence of phraseologically oriented activities in the language classroom. However, many of these approaches have simply suggested that formulaic language should be learned as lexicalized blocks, resulting in the replacement of word lists with formula lists. This type of pedagogical proposal is based, if only implicitly, on the assumption that formulaic language is stored and 
retrieved whole from memory, effectively functioning, from a psycholinguistic point of view, as a single word. Although there is indeed evidence to show that formulaic language is processed more quickly than matched non-formulaic sequences (Swinney and Cutler, 1979; Conklin and Schmitt, 2012), recent developments in largely usage-based approaches to linguistics may also provide a solid theoretical grounding for new reflections on phraseodidactics. Among these is Construction Grammar.

Construction Grammar is a label that covers several different related approaches, including Unification Construction Grammar (Fillmore et al., 1988), Cognitive Construction Grammar (Goldberg, 1995; 2006) and Radical Construction Grammar (Croft, 2001). These cognitively, functionally and usage oriented approaches share several basic tenets (Schulze and Penner, 2008), including:

- The basic unit of linguistic representation is the grammatical construction, where grammatical construction refers to any form-function pairing

- Form and meaning are considered to be nonmodular

- The constructions of any given language are organized into a structure

Coming back to the first point, the notion of construction covers a large and heterogeneous set, ranging in both size (from individual words to much longer stretches of language) and abstractness. Abstractness here refers to the lexical specification of different constructions. Thus, certain constructions (especially ones that we use with sufficient frequency) will be fully lexically specified. For instance, for a language teacher, a string such as the verb may be a fully lexically specified construction, because language teachers often talk about parts of speech. For a math teacher, however, such a string is not expected to be particularly frequent and, as such, probably does not constitute a lexically specified construction, instead being an example of a more abstract, open slot construction: the $+\mathrm{N}$. Moreover, either of these constructions (fully lexically specified or including an open slot) may be embedded in an even larger - and even more abstract - transitive construction: SUBJ + $\mathrm{V}+$ OBJ (e.g., John saw the dog). Within a construction grammar approach, the analyst and the teacher can choose to work at any - or all - of these levels, thus doing away with a strict grammar-lexicon opposition and opening the door to the study - and the teaching - of language systems in a more integrated (i.e., less modular) manner.

Moreover, for the language teacher, this type of approach allows for pedagogical applications that can complement the approach often adopted for formulaic sequences and which relies on simple memorization. More specifically, given that this approach recognizes abstract constructions at several levels throughout a language system, language teaching based on construction grammar principles can indeed target the memorization of fully lexically specified strings (e.g., the verb), but it can also take more abstract constructions as teaching targets. In such a case, the language teacher can work with learners to identify and understand the pairing between the form of the construction and its meaning. After identifying the construction and discussing its meaning, the teacher may ask learners to work on the generalization of the construction to additional appropriate forms. The advantage that such an approach has over one that is based wholly on memorization is two-fold. First, such an approach has the potential for generalization beyond tokens that are taught. Thus, if constructions are our teaching targets, the learner should be able to improve his phraseological competence without having to memorize countless individual instantiations of the construction in question. Second, in teaching learners to understand the formfunction connections, we are hopefully allowing for them to construct their own meaning instead of relying on lexicalized blocks. As pointed out by Chini (2001), but also by Myles et al. (1998) and Holme (2010a; 2010 b), reliance on lexicalized blocks can lead to a short-circuiting in the learner's construction of meaning, insofar as the learner is using blocks that they are incapable of modifying in order to match their own personal message and communication needs.

In what follows, I will begin by reviewing work done on constructions within L2 acquisition before turning to the few proposals for the teaching of an L2 relying on concepts from Construction Grammar. This will be followed by a presentation of two examples of pedagogical applications for the teaching of L2 French that find their inspiration in insights provided by a construction grammar approach to language.

\section{L2 Acquisition of Constructions}

To date, there have been relatively few attempts at examining the acquisition of an L2 from the perspective of Construction Grammar. Those that have adopted an explicitly construction grammar approach have, generally speaking, set out to determine whether non-native speakers (NNS) also have constructions in their L2. The question of 'having' constructions is essentially a psycholinguistic one. In other words, do constructions have a psychological reality in nonnative language systems? If this question is being posed for NNSs, it is at least in part because there is mounting evidence in favor of the construction as a 
psychologically real entity for NSs. Goldberg (2006), for instance, reviews numerous priming studies that have demonstrated that a construction such as the passive primes other passives. These findings lead Goldberg to conclude that "constructions can be primed, which means that the level of generalization involved in argument structure constructions is a useful one to acquire" (p. 125). In addition to priming studies, research with NSs has attempted to determine how NSs perceive semantic sameness, according to verb classes or constructions. Bencini and Goldberg (2000) presented participants with 16 sentences involving four verbs, each of which appeared in four different argument structure constructions. Participants were instructed to sort the cards into four piles according to overall meaning. Results from this experiment showed that seven participants sorted on the basis of verbs, six on the basis of constructions and the remaining four produced mixed sorts. The authors argue that verb-based sorting should be more perceptually salient and that, for this reason, the fact that construction-based sorts accounted for so many of the responses is significant.

Researchers interested in L2 acquisition from the point of view of Construction Grammar have used studies with NSs as a starting point in their attempt to determine whether constructions are real for L2 speakers. In particular, there have been many reproductions of the sorting study conducted by Bencini and Goldberg (2000). These studies have demonstrated that German speaking learners of English (Gries and Wulff, 2005), Chinese speaking learners of English (Liang, 2002; Goldberg, 2006) and Spanish speaking learners of English (Valenzuela Manzanares and RojoLópez, 2008) produce more construction-based sorts than verb-based sorts. Moreover, Liang found that construction-based sorts increased with proficiency. These results have been interpreted as evidence of the psychological status of constructions in the mind of the L2 learner.

This conclusion has found further support in priming and corpus-based studies. The processing of constructions by L2 learners of English has been investigated by Gries and Wulff (2005; 2009), who found evidence suggestive of construction-based priming. Valenzuela Manzanares and RojoLópez (2008) conducted corpus-based analyses of learner writing, which allowed them to identify a certain number of constructions. The results from a final acceptability judgment task were argued by the two authors to show the influence of "exemplar-specific constructional information" (p. 222). These results suggest that despite no explicit teaching that targets constructions, learners of an L2 are honing in on constructions and building representations of them.
It would seem then that the input received by L2 learners is sufficient to allow for them to build representations of constructions in their L2. A 2009 special issue published in The Modern Language Journal examined precisely this topic. The issue was devoted to input and L2 construction learning and revealed several relevant findings concerning the type of input helpful in the acquisition of constructions in an L2. In particular, it appears that both low- and high-variance input play important, and apparently complementary, roles in acquisition (Boyd and Goldberg, 2009). Low-variance input appears to be key in initial constructional category induction (Ellis and Ferreira-Junior, 2009). In other words, learners are better able to induce a construction if they are exposed to input in which a single proto-typical exemplar of that construction is present. On the other hand, high-variance input, which is input in which a large number of different token types instantiate a single construction, was shown to play a role in the generalization of a construction in the studies presented by Collins et al. (2009) and McDonough and Kim (2009). In describing this finding, Boyd and Goldberg write that "[a]s type frequency goes up, it becomes increasingly clear to learners that existing item-based constructional schemas can be generalized. This leads to the development of progressively more abstract representations, which can be deployed to produce and understand utterances that were not present in the input." (p. 420). A final finding of importance from the literature on the interaction between input and construction learning concerns cue validity. More specifically, Goldberg (2006) discussed the predictive value of verbs versus constructions for sentential meaning. Although both verbs and constructions can be good cues for meaning, this is not always the case. For example, verbs that appear in many constructions do not tend to have high cue validity. Goldberg reasons that "[s]ince most verbs appear in more than one construction with corresponding differences in interpretation, speakers would do well to learn to attend to the constructions." (2006, p. 106). Thus, verbs are not always good (or sufficient) indicators of sentential meaning, which implies that learners would do well to attend to the constructions in which they occur.

\section{Constructions in the L2 Classroom}

To the best of my knowledge, the only published accounts of attempts at applying a construction-based perspective to the L2 classroom have been couched in a Cognitive Linguistics framework (e.g., de Knop and 
de Rycker, 2008; Holme, 2010a; 2010b). In this section, I will concentrate on the two articles by Holme. In these two articles, Holme reflects on using construction grammar principles in order to develop a pedagogical model. Moreover, in Holme (2010a), the author reports the results of an intervention study. The study involved two treatments based on Construction Grammar and Cognitive Linguistic principles with groups of 16- and 17-year-olds studying English in Hong Kong. Each class had approximately 30 students and was compared to a control group. Holme identified his goals for the interventions as follows: “(1) Ensuring sufficient usage [of constructions] to foster entrenchment and relatedly; (2) encouraging to students to explore constructions as multiple tokens of a type" (2010a, p. 362).

Each intervention lasted four weeks with three hours of the intervention provided per week. In teaching constructions, Holme generally respected the following four-step progression: (a) construction specification (i.e., identifying the construction), (b) construction reproduction (e.g., using substitution tables in order to explore the meaning of the construction), (c) reinforcing meaning through conceptualization (e.g., using imagery) and finally (d) representing the construction's category meaning (e.g., students were asked to identify a prototype for a construction and to give it visual representation). The results from the two interventions showed that those learners who received a construction-based instruction showed some learning of the constructions targeted and showed overall more accurate writing. The finding that a construction-based intervention led to more accurate writing on the whole is especially exciting, as this suggests that the impact of the teaching went beyond the specific constructions targeted for instruction. The implementation of such an approach in L2 teaching would thus seem to merit our attention. In the following section, I attempt to contribute to this line of reflection with a description of two pedagogical interventions informed by construction-based reflections for a language that has not received much attention in this field, namely L2 French.

\section{Constructions in the L2 French Classroom}

Both interventions described were conceived for learners at a level B1 (intermediate level learners). In both cases, the interventions target constructions that should be at least in part familiar to the learners. In other words, the proposed interventions do not aim to present entirely novel material, but rather to enhance and to extend already existing knowledge (i.e., it is expected that for each example, certain tokens may be known by the learners and perhaps even constitute lexicalized blocks, that is, fully lexically specified constructions). The goals for the two examples are somewhat different. For example one (constructions for expressing feelings), the objective is to guide learners to recognize two related constructions and then to explore other tokens that can be used in those constructions in order to lead learners to a more schematic - and generalizable - knowledge of the constructions in question. In the second example, the goal is to take a low cue validity verb - rappeler - and to explore a set of the constructions in which it can participate, with an examination of the subsequent changes in meaning and form from one construction to another. Although the approaches adopted and the final goals differ between the two examples, in both cases, the first two steps outlined by Holme (2010a) in his intervention study are respected: A first phase in which the teacher and learners work together to specify the construction is followed by a second phase of construction reproduction. Moreover, both examples serve to demonstrate how a teacher of French might respect Holme's suggestion that "[ $\mathrm{t}]$ eachers should not be making decisions about whether to teach lexis or grammar so much as exploring how lexical meanings interface with grammatical ones, or teaching along the lexico-grammatical continuum" (2010b, p. 130).

\section{Example 1: Feeling + avec/de + Person/thing}

The first example will target two related open-slot constructions used in the expression of a feeling one person has towards a second person or thing. It should be noted that teaching the phraseology of emotion vocabulary in L2 French has already received considerable attention, including the publication of a valuable teaching manual (Cavalla and Crozier, 2005). The approach developed here is intended to complement this previous research. Whereas Cavalla and Crozier's book presents lexical patterns emotion by emotion, the current approach advocates drawing the learner's attention to construction patterns that cut across different emotion words. For this particular example, it is the association of the feeling with the following preposition that will constitute the targeted construction. Examples of the two constructions are shown in (4) and potential feelings or states are specified for each.
(4) Feeling + avec + person/thing
a. gentil 'nice'
b. méchant 'mean'
c. aimable 'amiable'
Feeling $+d e+$ person/thing




\section{a. peur 'afraid' \\ b. honte 'ashamed' \\ c. pitié 'pity'}

Prepositions tend to be considered an unruly part of a language system, not particularly amenable to explanation or to teaching beyond simple memorization. In the two constructions selected, the prepositions play a key role in constructing meaning: Whereas the first construction (with the preposition avec 'with') describes a transient feeling that person 1 feels towards person 2 or towards a thing (during a particular action or event, for example), the feeling described in the second construction has the potential to concern a more durable emotion (with the preposition de 'of'). This change in meaning is hypothesized to be linked to the change in preposition, as parallels with the same two prepositions can be found elsewhere in French. The goal of this intervention then is to lead learners to develop an understanding of these two constructions - meaning an understanding of their form and function - which is then intended to allow them to generalize the constructions to other appropriate feelings. In what follows, I will describe in detail how a teacher may first help learners to identify the form and function of the constructions under study (construction specification phase), followed by how a teacher might then work on leading learners to generalize this new form-function pairing to new tokens (construction reproduction phase).

The purpose of the construction specification phase is to work with learners to recognize the existence of the targeted constructions and to identify both the form and the function associated with them. For the particular case at hand, the teacher might first ask learners to brainstorm words for feelings in French. Working first on the specification of the form of the constructions, learners can be asked to create sentences with each feeling. Learners will then be asked to share their productions, feeling by feeling, with the teacher noting the learner suggestions on the board and making corrections where necessary. Note that depending on the feelings mentioned by the learners, other constructions related to the two target constructions may be identified, such as feeling + par + person/thing (dégoûté par quelqu'un/quelque chose disgusted by someone/something') or feeling + contre + person/thing (en colère contre quelqu'un/quelque chose angry at someone/something'). At this point, the teacher and learners can work together to group feelings by construction, with the teacher specifying that the remainder of the work will concentrate only on feeling + avec + person/thing and feeling + de + person/thing.

At this point, the construction specification phase turns to an examination of the function of each construction. Looking only at the learner-generated examples including de or avec, the teacher will then ask the class to make hypotheses concerning how to predict which type of feelings can be used with each preposition, with hypotheses being recorded on the board. Learners are expected to notice that the emotions expressed in the first construction (with avec) are more transient, whereas those in the second construction (with de) have the tendency to be more enduring. This work may be facilitated by providing learners with examples of certain tokens, as has been done for gentil avec 'nice to' and peur de 'afraid of' in Table 1.

These examples have been selected with the intention of highlighting the more transient nature of avec (note the presence of temporal specification with respect to the emotion of niceness in each example). Of course, gentil avec can be used to express more durative emotions, just as peur de can be limited in time. The purpose here, however, is to first aid learners in establishing basic patterns, which explains why no such examples are provided in this initial stage. All examples were taken from the French portion of the Web-As-Corpus Kool Yinitiative (WaCky), which constitutes a freely accessible, 1.6 billion word corpus constructed from the Web (for details, see Baroni et al., 2009).

Table 1. Corpus Examples of Two Constructions.

\begin{tabular}{ll}
\hline Gentil avec & Peur de \\
\hline $\begin{array}{l}\text { quand le serveur de free sera gentil avec moi, je mettrai } \\
\text { des tas de photos en ligne }\end{array}$ & il [l'animal] a ensuite peur de la mort, tout comme l'homme \\
'when the modem from Free is nice to me, I'll put a bunch & 'it [the animal] is moreover afraid of death, just like man' \\
of pictures online' & Je veux dire à tous les Français qui ont peur de l'avenir \\
la maîtresse a été gentille avec toi aujourd'hui ? & {$[\ldots]$ que je veux les protéger } \\
'was the teacher nice to you today?' & 'I want to say to all the French who are afraid of the \\
& future [...] that I want to protect them' \\
& sa mère était une grande voyante, et avait peur de tout tout le temps \\
'her mother was a great psychic reader and was afraid of everything
\end{tabular}


After this observation has been made, work on generalizing the new constructions will be undertaken (construction reproduction phase). Such work can take various forms, including but not limited to receptive selection tasks, the creation of substitution tables, gap-fill exercises, corpus-based exercises, etc. In all cases, the idea is to present the learners with new feelings and new contexts with regards to which they are required to use their knowledge of the two constructions in order to generalize beyond examples already examined in class. Finally, once the learners have a grasp on the difference between these two similar and related constructions, the teacher can use this understanding to discuss other examples concerning the prepositions found in these constructions, such as être capable de 'to be capable of,' where the use of de also tends to make reference to a durable quality.

\section{Example 2: The Verb Rappeler}

Whereas in the previous example, I attempted to demonstrate how one might target a particular construction (or set of constructions) in the L2 French language classroom with a view to generalization, in this second example, I will provide some ideas as to how construction-grammar insights may inform the teaching of words that have low cue validity. As remarked by Goldberg (2006), verbs can be very good indicators of sentential meaning. In such a case, we can speak of verbs with high cue validity. However, most verbs are used in more than one construction and certain verbs are used in many different constructions. For this latter group, the verb is less useful in predicting sentential meaning, making it a low cue validity verb. It is precisely in such situations that Goldberg suggests that construction learning will be of particular importance. From an L2 perspective, learners are generally confronted with many low cue validity verbs early on, as many of the most frequent verbs of a language are also used in multiple constructions. Although the learner may have the impression that he or she 'knows' the verb in question, chances are that they have only partial knowledge of the different form-function pairings in which it can be involved. In the following example, I attempt to show how a teacher might take a low cue validity verb as a starting point in order to elaborate a series of constructions around that verb. The example that will be given concerns the verb rappeler, meaning, among other things, 'to recall', 'to remind', 'to telephone again' and 'to remember'.

The first step in developing the pedagogical intervention described here involved a small-scale corpus-based investigation into the use of rappeler in the French portion of the WaCky corpus (Baroni et al., 2009). The goal of this investigation was to determine in which constructions rappeler is most frequently used in French more generally; this information was used to guide pedagogical decisions concerning the constructions to target (cf. O'Connor Di Vito, 1991). Thus, the first 200 occurrences of rappeler were analyzed according to the constructions each represented. Five constructions were identified, as shown in Table 2, of which three accounted for $97.5 \%$ of the total occurrences analyzed.

Table 2. Frequency of constructions involving rappeler

\begin{tabular}{|c|c|c|}
\hline Construction & Example & $\#$ \\
\hline $\begin{array}{l}\text { Person }+ \text { rappeler }+ \text { person } \\
\text { or animal }(+\grave{a}+\text { person })\end{array}$ & $\begin{array}{l}\text { quand Il rappelle à Lui un être cher à Son serviteur } \\
\text { 'when He calls back to Him a person cherished by His servant' }\end{array}$ & 1 \\
\hline Person + se rappeler $+q u e$ & $\begin{array}{l}\text { Haroutioun se rappelle que le patriarche arménien de Constantinople, } \\
\text { Monseigneur Zaven, a été évêque de Diarbékir avant la guerre } \\
\text { 'Haroutioun remembers that the Armenian patriarch of Constantinople, } \\
\text { Monseigneur Zaven, was Bishop of Diarbékir before the war' }\end{array}$ & 4 \\
\hline $\begin{array}{l}\text { Person }+ \text { se rappeler }+ \\
\text { someone or something }\end{array}$ & $\begin{array}{l}\text { Il suit très fidèlement le texte de Jacob et Wilhelm Grimm et il enrichit } \\
\text { chaque péripétie de mille digressions. Ainsi retrouve-t-on, si l'on se } \\
\text { rappelle cette histoire, la tartine de confiture, } \\
\text { 'He follows the text of Jacob and Wilhelm Grimm very faithfully and } \\
\text { he expands on each episode with thousands of digressions. In such a } \\
\text { way do we find, is we remember this story, the bread with jam,' }\end{array}$ & 20 \\
\hline $\begin{array}{l}\text { Person/something }+ \\
\text { rappeler }(+\grave{a}+\text { person }) \\
+ \text { que }\end{array}$ & $\begin{array}{l}\text { Le très intéressant texte d'Anne Dufresne rappelle que l'accès à l'information } \\
\text { disponible se fait au travers d'un certain nombre de filtres } \\
\text { 'The very interesting text by Anne Dufresne reminds us that access to } \\
\text { available information occurs across a certain number of filters' }\end{array}$ & 83 \\
\hline $\begin{array}{l}\text { Person/something }+ \\
\text { rappeler }+ \text { something } \\
(+\grave{a}+\text { person })\end{array}$ & $\begin{array}{l}\text { Ce nom me rappelle six années de ma tendre enfance } \\
\text { 'This name reminds me of six years of my early childhood' } \\
\text { Par sa décoration, la tour rappelle la tour Nord de la Cathédrale. } \\
\text { 'The decoration of the tower reminds one of the Northern tower of the Cathedral' }\end{array}$ & 92 \\
\hline Total & & 200 \\
\hline
\end{tabular}


Frequency of occurrence was used as a first selection criterion in selecting the target constructions for the pedagogical intervention to be developed. In this way, the first two constructions, for which only a total of five occurrences were found, were set aside, leaving us with three constructions. Two additional constructions were selected for study, bringing the total number of targeted constructions to five. These two additional constructions, which involve the verb rappeler in the sense to call back (on the telephone), were not attested in the small corpusbased study, a gap which is probably due to the fact that this particular use of the verb rappeler is largely limited to oral expression and most often when the two parties are already on the phone. It is thus not surprising that no examples were uncovered in a web-based corpus. This use, however, is arguably of interest to learners of L2 French, which is why constructions 1 and 2 (Table 3) were included in the current proposal.

In the construction specification phase, attention will first be focused on the four constructions presented in Table 3 (the fifth construction - Person/something + rappeler $(+\grave{a}+$ person $)+q u e-$ will be introduced later in the intervention). A small corpus of six examples, also provided in Table 3, will be used in this first phase.

To begin, learners will be given a card on which is written RAPPELLE. Working in small groups, they will be asked to create as many sentences as they can using this word. The sentences that are suggested will be written on the board. At this point, the teacher will distribute to each group a set of 11 additional cards on which will be written the other words in the six sentences shown in Table 3: je, me, te, on, se, cette, mes, decision, chanson, fille, vacances. The learners will be asked to create as many acceptable sentences as they can with these new words (plus rappelle). These proposals should minimally include the examples in Table 3 (although more are possible). Once again, the sentences created will be added to the board. At this point, learners will be asked to work together in small groups in order to study the resulting corpus of examples and to group sentences according to same overall meaning. Each small group will have to justify their decisions, explaining why they categorized certain examples together. Once the entire class has discussed and agreed upon a categorization of the examples, each category will be described with a schema (i.e., the open-slot constructions provided in Table 3). In order to elaborate the construction together, for each category, the class will be asked how many elements are necessary for expressions belonging to the category in question. For examples such as je te rappelle 'I'll call you back,' learners (with the help of the teacher) will be expected to observe that two elements - in addition to the verb rappeler - are necessary. The learners will then be asked to reflect on how to characterize these elements a does each refer to a person? a thing? an animal? When the direct object is expressed with a full noun instead of with a pronoun, is a preposition necessary? For the category of examples including je te rappelle (construction 1), learners are expected to recognize that each example involves two people: One who makes the call and a second who receives it and that this second person is not introduced with a preposition (unlike, for example, the synonym telephone 'to phone'), resulting in the schema Person 1 rappelle person 2.

Once the form of the basic construction has been specified for each of the first four categories, the teacher and learners must work together to specify the function and meaning of each construction. A first step in this process may ask learners to reflect on whether the use of these constructions is determined by context, with the expectation being that they will recognize that constructions 1 and 2 are generally used orally and on the telephone. In terms of working on meaning and function together, the teacher may ask learners to compose short scenarios in which the use of each construction would be appropriate. The teacher can begin by providing the learners with an example scenario for one of the constructions to use as a model and then ask them to compose, in their small groups, similar scenarios for the four constructions. For construction 1, an example of a scenario is provided in Fig. 1.

Table 3. Corpus for presentation of constructions involving rappeler

\begin{tabular}{|c|c|c|}
\hline \# & Construction & Corpus \\
\hline 1 & Person $1+$ rappeler + person 2 & $\begin{array}{l}\text { Je te rappelle } \\
\text { 'I'll call you back (on the telephone)' }\end{array}$ \\
\hline 2 & Person (plural) + se rappeler & $\begin{array}{l}\text { On se rappelle } \\
\text { 'We'll call each other (on the telephone)' }\end{array}$ \\
\hline 3 & Person + se rappeler + someone/something & $\begin{array}{l}\text { Je me rappelle cette décision } \\
\text { 'I remember this decision' } \\
\text { Je me rappelle cette fille } \\
\text { 'I remember this girl' }\end{array}$ \\
\hline 4 & Person/something + rappeler + something $(+\grave{a}+$ person $)$ & $\begin{array}{l}\text { Je (te) rappelle cette decision } \\
\text { 'I remind (you) of this decision' } \\
\text { Cette chanson me rappelle mes vacances } \\
\text { 'This song reminds me of my vacation' }\end{array}$ \\
\hline
\end{tabular}




Person1 + rappeler + person 2
Personne 1 et personne 2 parlent au téléphone. La conversation n'est pas finie,
mais personne 1 doit raccrocher. Personne 1 dit à personne 2 : je te rappelle
'Person 1 and person 2 are talking on the telephone. The conversation is not
finished, but person 1 must hang up. Person 1 says to person $2:$ I'll call you
back'

Fig. 1. Example scenario for construction 1

This work on the form-function connections associated with each construction provides the teacher with the occasion to show learners how a construction can force a meaning that may not appear to be present in a lexical item at the outset. Within the context of the current pedagogical intervention, the teacher can address this point with the example on se sms? ('we'll send each other a text message?'). After writing this example on the board, learners would be required to identify the construction used in this sentence and to relate it to the constructions in which rappeler can be found. In this case, learners are expected to remark that the noun SMS 'text message' is inserted into a slot generally reserved for verbs in construction 2. From there, the teacher would ask learners to explain the meaning of this question in their own words. The expected answer would recognize that this question is interpreted to mean that the two people will contact each other via SMS, despite the fact that SMS is not a verb in French. Thus, it is only thanks to the use of construction 2 (Person (plural) + se V) that the noun $S M S$ is imbued with the meaning of reciprocal communication, thus showing the important role that can be played by constructions in building meaning.

After establishing the form and function of the first four constructions, the focus of the intervention moves to the construction reproduction phase. One approach in this phase could ask learners to use the constructions themselves, with some specific substitutions or additions imposed by the teacher. In terms of substitutions, learners may be asked to create examples for each construction using the subject $J e$ 'I', in which case learners are expected to observe that the first person singular - and, indeed, any semantically singular subject - is strange in construction 2 because of its reciprocal meaning. As concerns additions, the teacher may ask the learners to attempt to create examples of each construction in which the complementizer que has been added after the verb and to determine whether the resulting structure is possible. Learners should note that this is not possible in constructions 1 and 2, where rappeler obligatorily takes a direct object, whereas it is possible in constructions 3 and 4, where the subordinate clause introduced by que can replace the direct object. At this point, the teacher would need to point out that
Person/something + rappeler $(+\grave{a}+$ person $)+q u e$, the fifth construction targeted in this intervention, is a particularly frequent construction for the verb rappeler.

Finally, learners may be asked to further appropriate the five new constructions in which rappeler appears by comparing them to how related verbs such as se souvenir 'to remember', appeler 'to call', telephone 'to telephone' are expressed. The goal is for learners to determine whether verbs with similar meanings are used in similar constructions and, if not, in what constructions these new verbs appear. For this phase, the teacher may either provide the learners with a set of examples from which to work or may ask students to consult a corpus directly. Such an approach can be either deductive, whereby the learners would start with the hypothesis that each new verb is used in the same constructions as rappeler and they would have to check this hypothesis against corpus evidence, or inductive, in which examples of each new verb would be examined by learners and grouped according to construction, thus identifying the constructions in which appears each verb (Chambers, 2005). Once learners have determined how the constructions in which rappeler appears to differ from, for example, those in which téléphoner appears, the teacher would then ask learners to create their own examples for each of these constructions.

\section{Discussion and Conclusion}

If Construction Grammar has become a force to be reckoned with in the field of linguistics, its impact in the field of L2 didactics remains, for the moment, less pronounced. Apart from the volume edited by de Knop and de Rycker (2008) and the two articles by Holme (2010a; 2010 b), few attempts have been made to demonstrate the interest that construction-grammar insights can hold for language teachers. In the present article, I have attempted to contribute to this field of inquiry by providing two examples of pedagogical applications informed by Construction Grammar. My aim was twofold. First, I hoped to extend the current constructiongrammar informed reflection to French, a language that has not received much attention in this discussion. Second, I intended to demonstrate how findings from 
the psycholinguistic literature concerning constructions for NSs and NNSs alike may inform pedagogical decisions. To this end, I presented two concrete pedagogical applications. In the first case, the goal was to move from what was hypothesized to be a small set of fully lexically determined constructions to a more schematic, abstract and especially generalizable knowledge of constructions used in discussing feelings. After having identified and defined the targeted constructions with the learners, it was suggested that this goal could be accomplished by exposing learners to a wide variety of new lexical items, showing them - and inciting them to test this themselves - that many different lexical items could enter into the identified constructions. As shown in the L2 research on input and constructions, providing learners with input showing a large number of token types for a given construction (i.e., high variance input) is essential for generalization of constructions. It is precisely this generalization that was targeted in this example and that Holme (2010a) concludes to be particularly important in L2 teaching: "Constructions need to be explored more from the perspective of their schematicity and less from that of their existence as fixed expressions."

In the second example developed, the goal was somewhat different. This time, a single verb was selected. The verb in question - rappeler - occurs in a variety of constructions in French, of which five were identified as being of particular relevance for learners at a B1 level. The goal of this intervention was essentially to aid the learner in building up constructions around this particular verb. Given that rappeler can occur in numerous constructions, it is essential that learners understand that this verb does not have a single, immutable meaning, regardless of context. Instead, the goal was to lead learners to understand that meaning changes as a function of construction and that these constructions may ultimately be better indicators of overall sentential meaning that the single verb rappeler. The importance of the construction in overall meaning was particularly clear in the final step of the pedagogical intervention, which involved exploring how other verbs also enter into some (but not all) of these same constructions. For both interventions detailed in this article and for other such constructionbased approaches to language teaching, the goal is to allow learners to build up constructions and to generalize them in their L2. Tomasello et al. (1998, p. 433) would refer to this goal simply as linguistic competence, as for him "[1]inguistic competence is nothing more or less than competence with the constructions of a particular natural language." In light of the promising experimental results reported in Holme (2010a), researchers in the field of L2 teaching and didactics may do well to consider Tomasello's view on what it means to know a language and, thus, to set about developing and testing more construction-grammar based pedagogical approaches to the teaching of an L2.

\section{References}

Baroni, M., S. Bernardini, A. Ferraresi and E. Zanchetta, 2009. The waCky wide web: A collection of very large linguistically processed web-crawled corpora. Lang. Resour. Evaluat., 43: 209-226.

DOI: $10.1007 / \mathrm{s} 10579-009-9081-4$

Bencini, G. and A.E. Goldberg, 2000. The contribution of argument structure constructions to sentence meaning. J. Memory Lang., 43: 640-651. DOI: $10.1006 /$ jmla.2000.2757

Boyd, J. K. and A.E. Goldberg, 2009. Input effects within a constructionist framework. Modern Lang. J., 93: 418-429. DOI: $10.1111 /$ j.1540-4781.2009.00899.x

Cavalla, C. and E. Crozier, 2005. Emotions Sentiments: Nouvelle Approche Lexicale du FLE, Livre de L'élève. 1st Edn., Presses Universitaires Grenoble, Grenoble, ISBN-10: 270611262X, pp: 87.

Chambers, A., 2005. Integrating corpus consultation in language studies. Lang. Learn. Technol., 9: 111-125.

Chini, D., 2001. Détournement Didactique de la Locutionnalité: Les Blocs Lexicalisés. In: La Locution et la Périphrase du Lexique à la Grammaire, Tollis, F. (Ed.), L'Harmattan, Paris, pp : 37-53.

Collins, L., P. Trofimovich, J. White, W. Cardoso and M. Horst, 2009. Some input on the easy/difficult grammar question: An empirical study. Modern Lang. J., 93: 336-353.

DOI: $10.1111 /$ j.1540-4781.2009.00894.x

Conklin, K. and N. Schmitt, 2012. The processing of formulaic language. Ann. Rev. Applied Linguist., 32: 45-61. DOI: 10.1017/S0267190512000074

Croft, W., 2001. Radical Construction Grammar: Syntactic Theory in Typological Perspective. 1st Edn., Oxford University Press, Oxford, ISBN-10: 9780198299547 , pp: 448.

de Knop, S. and T. de Rycker, 2008. Cognitive Approaches to Pedagogical Grammar: A Volume in Honour of René Dirven. 1st Edn., Mouton de Gruyter, Berlin, ISBN-10: $311019595 X$, pp: 342.

Edmonds, A., 2013. Parfaitement Sensé-La Préférence Sémantique et l'Enseignement des Collocations en L2. In: Enseigner le Lexique, $\mathrm{n}^{\circ} 5$ de la collection de l'AiRDF, Garcia-Debanc, C., C. Masseron and C. Ronveaux (Eds.), Presses Universitaires de Namur, Namur, pp: 131-151. 
Ellis, N.C. and F. Ferreira-Junior, 2009. Construction learning as a function of frequency, frequency distribution and function. Modern Lang. J., 93: 370-385. DOI: 10.1111/j.1540-4781.2009.00896.x

Fillmore, C.J., P. Kay and M.C. O’Connor, 1988. Regularity and idiomaticity in grammatical constructions: the case of Let alone. Language, 64: 501-538. DOI: $10.2307 / 414531$

Goldberg, A.E., 1995. Constructions: A Construction Grammar Approach to Argument Structure. 1st Edn., University of Chicago Press, Chicago, ISBN-10: 0226300862, pp: 271.

Goldberg, A.E., 2006. Constructions at Work: The Nature of Generalization in Language. 1st Edn., Oxford University Press, Oxford, ISBN-10: 0199268525, pp: 290.

González-Rey, I., 2010. La Phraséodidactique en Action: les Expressions Figées comme Objet d'Enseignement. La Clé des Langues (Lyon: ENS LYON/DGESCO).

Gries, S.T. and S. Wulff, 2005. Do foreign language learners also have constructions? Ann. Rev. Cognitive Linguist., 3: 182-200.

DOI: 10.1075/arcl.3.10gri

Gries, S.T. and S. Wulff, 2009. Psycholinguistic and corpus-linguistic evidence for L2 constructions. Ann. Rev. Cognitive Linguist., 7: 163-186. DOI: 10.1075/arcl.7.07gri

Holme, R., 2010a. A construction grammar for the classroom. Int. Rev. Applied Linguist. Lang. Teach., 48: 355-377. DOI: 10.1515/iral.2010.015

Holme, R., 2010b. Construction grammars: Towards a pedagogical model. AILA Rev., 23: 115-133. DOI: 10.1075/aila.23.07hol

Lewis, M., 1993. The Lexical Approach. 1st Edn., Teacher Training Publications, Hove.

McDonough, K. and Y. Kim, 2009. Syntactic priming, type frequency and EFL learners' production of whquestions. Modern Lang. J., 93: 386-398. DOI: $10.1111 / \mathrm{j} .1540-4781.2009 .00897 . \mathrm{x}$
Myles, F., J. Hooper. and R. Mitchell, 1998. Rote or rule? Exploring the role of formulaic language in classroom foreignlanguage learning. Lang. Learn., 48: 323-363. DOI: 10.1111/0023-8333.00045

O'Connor Di Vito, N., 1991. Incorporating native speaker norms in second language materials. Applied Linguist., 12: 383-396. DOI: $10.1093 /$ applin/12.4.383

Pawley, A.K. and F.H. Syder, 1983. Two Puzzles for Linguistic Theory: Nativelike Selection and Nativelike Fluency. In: Language and Communication, Richards, J.C. and R.W. Schmidt (Eds.), Longman, London, pp: 191-225.

Schulze, M. and N. Penner, 2008. Construction grammar in ICALL. Comput. Assisted Lang. Learn., 21: 427440. DOI: $10.1080 / 09588220802447727$

Swinney, D. and A. Cutler, 1979. The access and processing of idiomatic expressions. J. Verbal Learn. Verbal Behav., 18: 523-534. DOI: 10.1016/S0022-5371(79)90284-6

Tomasello, M., J. Call and B. Hare, 1998. Five primate species follow the visual gaze of conspecifics. Animal Behav., 55: 1063-1069. DOI: 10.1006/anbe. 1997.0636

Valenzuela Manzanares, J. and A.M. Rojo López, 2008. What Can Language Learners Tell us about Constructions? In: Cognitive Approaches to Pedagogical Grammar: A Volume in Honour of René Dirven, De Knop, S. and T. De Rycker (Eds.), Mouton de Gruyter, Berlin, pp: 197-230.

Wray, A., 2000. Formulaic sequences in second language teaching: Principle and practice. Applied Linguist., 21: 463-489. DOI: 10.1093/applin/21.4.463

Wray, A., 2013. Formulaic language. Lang. Teach., 46: 316-334. DOI: 10.1017/S0261444813000013 